\title{
"AIR TANGAN IBU" DALAM BUDAYA MAKANAN MELAYU MENURUT PERSPEKTIF ISLAM BERDASARKAN CERPEN MELAYU PILIHAN
}

\section{(Air Tangan Ibu in Malay Culinary Culture and from an Islamic Perspective as Represented in Selected Malay Novels)}

Kamariah Kamarudin*

kkamaria@upm.edu.my

Jabatan Bahasa Melayu, Fakulti Bahasa Moden dan Komunikasi, Universiti Putra Malaysia

Pabiyah Hajimaming@Toklubok

pabiyah@upm.edu.my

Jabatan Bahasa Asing, Fakulti Bahasa Moden dan Komunikasi, Universiti Putra Malaysia

Corresponding author (Pengarang koresponden): *

To cite this article (Rujukan artikel ini): Kamariah Kamarudin \& Pabiyah Hajimaming@Toklubok. (2021).“Air Tangan Ibu dalam Budaya Makanan Melayu menurut Perspektif Islam Berdasarkan Cerpen Melayu Pilihan. Malay Literature, 34(1), 103-116. http://doi.org. 10.37052/ml34(1)no6

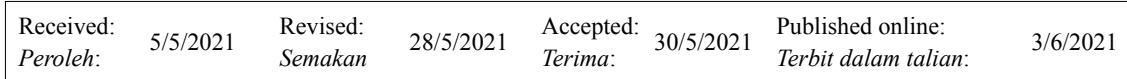

\footnotetext{
Abstrak

Dalam budaya Melayu, konsep “air tangan ibu” secara umumnya dikenali sebagai usaha mulia seorang yang bergelar wanita yang memiliki anak untuk menyediakan hidangan dalam masakan. Namun begitu, secara falsafahnya "air tangan ibu" bukan sekadar berbentuk hidangan dalam masakan bahkan sebenarnya merupakan aliran kasih sayang, kesungguhan, dan ketulusan hati seseorang ibu yang menyediakan makanan untuk 
anaknya. Maka, dengan hati itulah sebenarnya yang mengalirkan "air tangan ibu" yang menjadi obor kekuatan kepada seseorang anak untuk mengingati dan mengenangi jasa ibunya. Malahan, dalam konteks Islam, falsafah "air tangan" ini juga dapat disejajarkan dengan dorongan Rasulullah SAW agar setiap manusia di muka bumi ini memperelok kerja seharian. Oleh itu, kajian ini meneliti cerpen Melayu pilihan yang memperlihatkan kreativiti pengarang mengutarakan "air tangan ibu" menerusi menu yang disajikan dalam karya masing-masing. Kajian akan merungkai konsep "air tangan ibu" sebagai tunjang pendidikan, sebagai pemberi peringatan dan sebagai pembentuk akhlak berdasarkan cerpen Kerana "Kuih Koci" (Fathul Khair Mohd Dahlan), "Bihun Goreng Berkuah Laksa" (Nordin Saad) dan "Serondeng Nasi Pulut" (Jamilah Epin). Berdasarkan kajian, jelas menunjukkan bahawa konsep "air tangan ibu" dalam budaya Melayu menyerlahkan keupayaan pengarang mengutarakan kreativiti makanan Melayu dalam cerpen-cerpen masingmasing, yang akhirnya memberikan makna dalam kehidupan manusia sejagat.

Kata kunci: “Air tangan ibu”, budaya makanan Melayu, cerpen-cerpen Melayu pilihan

\begin{abstract}
In Malay culture, the concept of air tangan ibu (mother's handiwork) generally refers to the noble effort of a woman in cooking dishes for her children. Philosophically, however, air tangan ibu does not merely refer to a mother's cooking but encompasses the love, earnestness and sincerity of the mother in preparing dishes for her children. It is this emotion that flows through it that will lead a child to remember its mother and her sacrifices. In fact, in the context of Islam, the philosophy of air tangan ibu is in line with the encouragement of the Rasulullah s.a.w. that everyone on this Earth should give their best in their everyday occupation. Therefore, this study analyses selected Malay short stories that display their writer's creativity through the dishes highlighted in each of these works. The study unravels the concept of "air tangan ibu" as a backbone of education, as a reminder, and as a character-shaping force, based on the short stories "Kerana Kuih Koci" (Fathul Khair Mohd Dahlan), "Bihun Goreng Berkuah Laksa" (Nordin Saad) and "Serondeng Nasi Pulut" (Jamilah Epin). The study makes clear that air tangan ibu in Malay culture highlights the ability of writers to showcase the culinary creativity of the Malays in each of these short stories, which ultimately has a universal meaning to people in their lives the world over.
\end{abstract}


KAMARIAH KAMARUDIN AND PABIYAH HAJIMAMING@TOKLUBOK

Keywords: Air tangan ibu, Malay culinary culture, selected Malay short stories

\section{PENDAHULUAN}

Peranan seorang ibu sangat penting dalam institusi kekeluargaan. Hal ini demikian kerana ibu merupakan penggerak kepada keunggulan kehidupan, sementelahan untuk membentuk keperibadian mulia anak-anak. Peranan ibu dalam pendidikan bagi sesebuah keluarga bukan sekadar bersifat nilai luaran bahkan menjurus kepada nilai dalaman anak-anak. Segala selok-belok urusan berkaitan dengan anak-anak dibangunkan dan disediakan oleh ibu dengan kecekalan dan kesabaran. Amanah yang tersandang di bahu ibu keperibadian dan kewibawaan seorang wanita yang mulia dan terpuji. Atas musabab itu, pepatah Melayu ada menyebut "syurga terletak di telapak kaki ibu" lantaran peranan dan pengorbanan seorang ibu yang amat besar dalam sesebuah kekeluargaan.

Malahan dalam menguruskan hal ehwal rumahtangga, khususnya menyediakan makanan, peranan seorang ibu sangat diutamakan. Daripada sekecil-kecil masakan sehingga kepada menu yang enak dan sajian yang lengkap, masakan ibu tidak ada tandingan. Usaha seorang ibu dalam hal menyempurnakan hidangan untuk keluarga sesungguhnya merupakan pengorbanan yang sangat bermakna. Oleh itu, dalam konteks perkembangan sastera Melayu tanah air, watak dan perwatakan ibu sering ditonjolkan pengarang bagi menyerlahkan sosok sahsiah yang harus dijadikan suri teladan kepada pembaca. Peranan ibu sebagai wanita yang menjadi cerminan kemuliaan ditampilkan oleh pengarang dalam novel Melayu tanah air. Antara karya sastera Melayu yang menampilkan ibu sebagai watak utamanya termasuklah, Diari Bonda (Rohani Din, 2005), Airmata Ibu (Soo Cham, 2007), Sesuci Kasih Bonda (Ilani Mysara, 2010), Diari untuk Ibu (Iwan Ghazali, 2013) dan Ibu (Abdul Rashid Ngah, 2014).

Sejajar dengan itu, dalam karya sastera baik tradisional atau moden, makanan merupakan antara elemen yang dimasukkan dalam sesebuah karya kerana aktiviti makan merupakan salah satu perkara yang wajib dilakukan oleh manusia dalam kehidupan seharian mereka(Suhaila Mohamed \& Shaiful Bahri Md Radzi, 2015). Untuk itu, dalam perkembangan sastera Melayu moden pula, terdapat cerpen yang memperkatakan tentang sajian makanan Melayu yang disuguhkan oleh pengarang tanah air. Cerpen tersebut mengemukakan budaya makanan Melayu sebagai tema penceritaan, dan nama sajian makanan 
Melayu sebagai tajuk cerpen untuk disampaikan kepada khalayak pembaca. Antara cerpen yang berkisar tentang makanan Melayu termasuklah Jeruk Maman Emak (Lee Keok Chih), Lemang Nan Sebatang (Nisah Haron), Sesar Unjur Kampung Belawai (Amaruszati Noor Rahim), Tulang Pekasam Ikan Puyu (Azizi Haji Abdullah), Gulai Tempoyak Ikan Sebarau (Malim Ghozali Pk), Cinta Gendang Kasturi (Faisal Tehrani), Pulut Serunding Buat Nazihah (Shahkang), Setalam Halwa Maskat (Shahkang), dan lain-lain.

Sehubungan itu, artikel ini akan merungkaikan konsep "air tangan ibu" dalam budaya makanan Melayu menurut perspektif Islam berdasarkan cerpen-cerpen Melayu terpilih.

\section{OBJEKTIF KAJIAN}

Objektif kajian ini adalah untuk mengkaji peranan ibu yang memberi pendidikan kepada anak-anaknya menerusi penyediaan sajian makanan untuk keluarga dalam budaya makanan Melayu. Oleh itu, tiga buah cerpen, iaitu "Kerana Kuih Koci" (Fathul Khair Mohd Dahlan, 2016), "Bihun Goreng Berkuah Laksa" (Nordin Saad, 2015) dan "Serondeng Nasi Pulut" (Jamilah Epin, 2016) dijadikan bahan kajian. Selain itu, kajian ini juga akan menganalisis ketiga-tiga buah cerpen tersebut berdasarkan konsep "air tangan" ibu menurut perspektif Islam sebagai tunjang pendidikan, sebagai pemberi peringatan dan sebagai pembentuk akhlak terhadap anak-anak dalam sebuah institusi kekeluargaan.

\section{METODOLOGI KAJIAN}

Reka bentuk kajian ini ialah bersifat kepustakaan melalui pembacaan bukubuku ilmiah, kajian terdahulu serta pandangan daripada tokoh pengajian kebudayaan, kesusasteraan dan agamawan.

\section{Data kajian}

Data diambil daripada tiga buah cerpen, iaitu "Kerana Kuih Koci”, "Bihun Goreng Berkuah Laksa" dan "Serondeng Nasi Pulut". Cerpen "Kerana Kuih Koci" terdapat dalam Kumpulan Cerpen Remaja Sfera Bersegi 5 (Fathul Khair Mohd Dahlan, 2016), "Bihun Goreng Berkuah Laksa" dalam Kumpulan Cerpen Bihun Goreng Berkuah Laksa (Nordin Saad, 2015) dan "Serondeng Nasi Pulut" dalam Kumpulan Cerpen Remaja Serondeng Nasi Pulut (Jamilah Epin, 2016). Ketiga-tiga buah kumpulan cerpen ini diterbitkan oleh Institut Terjemahan \& Buku Malaysia. 


\section{PERANAN IBU MENURUT PERSPEKTIF ISLAM}

Wanita antara makhluk ciptaan Tuhan yang paling agung di dunia lantaran memiliki keistimewaannya yang tersendiri. Wanita berperanan bukan sekadar sebagai seorang anak perempuan, bahkan apabila mendirikan rumah tangga akan berfungsi sebagai seorang isteri, dan ibu. Wanita Muslimah khususnya disebut dalam al-Quran menerusi surah khas, iaitu Surah an-Nisa' memperkatakan tentang selok-belok tanggungjawab wanita dalam kehidupan. Malahan dalam al-Quran juga disebut istilah "umm", iaitu ibu dalam pelbagai bentuk sebanyak 35 kali, yang seterusnya bermakna dituju atau menjadi arah kerana ibu dinamai "umm", akan menjadi arah yang dituju oleh anak. ${ }^{1}$ Selain itu, Sayyid Qutb dalam kitab Fi Zilal Al-Quran turut menyatakan bahawa ibu berperanan besar dalam pendidikan anak-anak bermula dengan penyusuan bayi pada peringkat dua tahun pertama, diikuti dengan belaian dan kasih sayang yang berterusan (Asyraf, Wan Ibrahim \& Zainab, 2010).

Hal ini turut diperkukuh dalam Surah al-Najm ayat 32 yang maksudnya: "Ketika kamu masih janin dalam perut ibumu." Selain itu, menerusi Surah al-Nahl, ayat 78 juga memperkatakan tentang ibu, yang maksudnya: "Dan Allah mengeluarkan kamu daripada perut." Seterusnya, Surah al-Ahqaf ayat 15 yang bermaksud: "Kami perintahkan kepada manusia supaya berbuat baik kepada dua orang ibu bapanya, ibunya mengandungnya dengan susah payah, dan melahirkannya dengan susah payah (pula). Mengandungnya sampai menyusunya adalah tiga puluh bulan." Seterusnya Surah Luqman, ayat 14, yang bermaksud: "Dan Kami perintahkan kepada manusia (berbuat baik) kepada dua orang ibu bapanya; ibunya telah mengandungnya dalam keadaan lemah yang bertambah-tambah, dan menyusunya dalam dua tahun."

Sementelahan itu, dalam sebuah hadis turut memperkatakan keutamaan memuliakan ibu, yang bermaksud:

"Daripada Abu Hurairah, ia berkata: Seseorang datang kepada Rasulullah SAW dan berkata, wahai Rasulullah! kepada siapakah aku harus berbakti pertama kali? Nabi menjawab, ibumu! Orang tersebut bertanya kembali, kemudian siapa lagi? Beliau menjawab, ibumu! Orang tersebut bertanya kembali kemudian siapa lagi? Nabi menjawab, kemudian kepada ayahmu." (Hadis Riwayat Bukhari, 5971 dan Hadis Riwayat Muslim, 2548).

Berdasarkan terjemahan ayat al-Quran dan hadis Nabi SAW jelas menunjukkan martabat ibu sangat tinggi dan peranannya yang besar dalam sesebuah keluarga. Martabat ibu diletakkan pada tempat yang paling tinggi lantaran jasanya dalam melahirkan, mengasuh dan membimbing anak-anak 
sehingga dewasa. Maka, peranan utama ibu dalam Islam dapat dikategorikan kepada tiga bahagian (Siti Nur Husna, Mohd Izhar Ariff, Muhammad Adnan, 2017), iaitu:

\section{Ibu yang prihatin dalam mendidik anak-anak}

Hal ini terungkap dalam Surah al-Furqan ayat 74 sebagaimana terjemahan berikut: "Dan juga mereka (yang diredai Allah itu ialah orang) yang berdoa dengan berkata: "Wahai Tuhan kami! Berilah kami beroleh dari isteri-isteri dan zuriat keturunan kami: Perkaraperkara yang menyukakan hati melihatnya, dan jadikanlah kami imam ikutan bagi orang yang (mahu) bertakwa"

2. Ibu yang prihatin dalam memberikan peringatan kebaikan anak-anak Hal ini terungkap dalam Surah Luqman ayat 16 sebagaimana terjemahan berikut: "Luqman menasihati anaknya dengan berkata: Wahai anak kesayanganku, sesungguhnya jika ada sesuatu perkara (yang baik atau yang buruk) sekalipun seberat biji sawi, serta ia tersembunyi di dalam batu besar atau di langit ataupun di bumi, sudah tetap akan dibawa oleh Allah (untuk dihakimi dan dibalas-Nya); kerana sesungguhnya Allah amat halus pengetahuan-Nya lagi amat meliputi segala yang tersembunyi."

3. Ibu yang prihatin dalam membentuk akhlak mulia anak-anaknya Hal ini terungkap dalam Surah Luqman, ayat 18-19 sebagaimana terjemahan berikut:

"Dan janganlah engkau memalingkan mukamu (kerana memandang rendah) kepada manusia, dan janganlah engkau berjalan di bumi dengan berlagak sombong; sesungguhnya Allah tidak suka kepada tiap-tiap orang yang sombong takbur, lagi membanggakan diri. "Dan sederhanakanlah langkahmu semasa berjalan, juga rendahkanlah suaramu (semasa berkata-kata), sesungguhnya seburuk-buruk suara ialah suara keldai”.

Oleh itu, peranan ibu dalam perspektif Islam ini menyerlahkan pengorbanan seorang wanita yang sanggup menyumbang bakti kepada ahli keluarga tanpa mengenal penat lelah melainkan sifat keikhlasan. Seseorang wanita yang sabar dan ikhlas mendidik, memberikan peringatan dan membentuk akhlak yang baik kepada anak-anak memperlihatkan jiwanya yang luhur sejajar dengan ganjaran pahala yang dikurniakan kepadanya. Lantaran itu, dalam konteks budaya Melayu terserlah kesungguhan seorang ibu yang bertungkus lumus menyediakan makanan untuk anak-anak kerana secara lazimnya hidangan 
tersebut dapat mengikat hubungan yang padu dalam hati kedua-dua pihak. Nilai kasih sayang seseorang wanita yang bergelar "ibu" yang patuh pada perintah agama, khususnya yang memegang status sebagai wanita solehah dan ibu mithali, sudah pasti menuntut pengorbanan luar biasanya. Oleh itu, istilah "air tangan ibu" dalam budaya makanan Melayu menunjukkan keupayaan seseorang ibu yang sanggup menyediakan hidangan untuk anakanak demi kasih sayang kepada zuriatnya walaupun sarat dengan tugasan dan kerjayanya untuk membesarkan anak-anak. Para ibu yang menyedari hakikat tanggungjawab dalam usaha mendidik anak-anak akan bersiap siaga melakukan yang terbaik untuk keluarganya dalam hal ehwal rumah tangga dan khususnya dalam penyediaan hidangan makanan.

\section{“AIR TANGAN IBU” DALAM BUDAYA MAKANAN MELAYU}

Didapati pelbagai menu dalam budaya makanan Melayu hasil daripada masakan para ibu untuk anak-anak dan keluarga. Dalam budaya makanan Melayu, lazimnya hidangan yang dimasak para ibu bersifat lauk-pauk atau kuih-muih yang diwarisi secara turun-temurun. Rasanya yang lazat dan baunya yang menyelerakan menjadi sebab utama mengapa makanan tradisi Melayu ini masih digemari hingga pada hari ini. Malahan kelazatannya tidak boleh ditandingi oleh makanan moden. Hidangan lauk-pauk dan kuih-muih tradisional juga mewakili demografi negeri dan negara masing-masing. Di Malaysia misalnya, setiap negeri mempunyai makanan tradisinya yang tersendiri. Sebagai contohnya Pulau Pinang terkenal dengan laksanya, Perak dengan tempoyaknya, Kelantan dengan budunya, Melaka dengan cencaloknya, Johor dengan lontongnya, Negeri Sembilan dengan masak lemak cili api dan lain-lain lagi (Che Wan Jasimah, 2009).

Malahan, dalam hidangan kuih-muih, sajian yang dihasilkan dalam budaya Melayu sangat mengujakan. Hal ini demikian kerana bahan-bahan yang diadun menggunakan sumber alam yang mudah terdapat di tanah air, seperti pisang, ubi kayu, ubi keledek, daun pisang, daun pandan dan sebagainya. Sebagai contoh, kuih akok, kuih seri muka, kuih talam ubi, kuih lepat pisang, kuih keria dan banyak lagi masakan yang berasaskan alam yang dihasilkan oleh budaya Melayu. Didapati kuih-muih tradisional tersebut diwarisi secara turun-temurun yang memperlihatkan "air tangan" seorang ibu dalam sesebuah rumah tangga.

Air tangan ibu dalam budaya makanan Melayu bukanlah bermakna "air" dalam erti kata yang fizikal, namun merupakan aliran kasih sayang, kesungguhan, keceriaan dan ketulusan hati seorang ibu yang memasak 
untuk anaknya. Hati itulah yang mengalirkan "air tangan" yang seterusnya menjadi pengikat kasih sayang seorang ibu dengan anak-anaknya. Jadi, pada hakikatnya, "air tangan" merupakan aliran kasih sayang semasa ibu memasak untuk anak-anaknya. Hal ini juga sejajar dengan terjemahan hadis sebagaimana berikut: "Bahawasanya Allah SWT suka apabila seseorang daripada kamu membuat sesuatu kerja, dia memperelokkan kerjanya" (Hadis Riwayat al-Baihaqi). Hadis tersebut merupakan falsafah di sebalik "air tangan ibu" sebagai dorongan kepada para ibu untuk melakukan masakan yang terbaik untuk anak-anaknya. Hal ini demikian kerana peranan seorang ibu seperti yang dituntut dalam Islam amatlah besar dan menyeluruh. Ibu dituntut untuk menguruskan semua hal ehwal kehidupan yang meliputi dalaman dan luaran, rohani dan jasmani.

\section{“Air Tangan Ibu" dalam Budaya Makanan Melayu Berdasarkan Cerpen-cerpen Melayu Pilihan}

\section{(1) "Air tangan ibu" sebagai tunjang pendidikan}

Berdasarkan cerpen "Bihun Goreng Berkuah Laksa" memperlihatkan "air tangan ibu" sebagai tunjang dalam pendidikan, khususnya dalam usaha mengasuh anak-anak dengan menerapkan peribadi mulia. Cerpen ini menampilkan watak ibu yang mendidik anak perempuannya agar mencintai warisan makanan Melayu, iaitu bihun goreng berkuah laksa yang dipelajarinya sejak turun-temurun. Walaupun ibunya telah meninggal dunia, namun anak perempuannya tetap mengenang segala didikan dan ilmu yang dipelajari daripada ibunya itu. Malahan yang paling mengujakan tentulah ilmu masakan yang diperturunkan oleh ibunya kepada anak perempuannya dalam hal menguruskan hal ehwal rumah tangga. Ternyata "air tangan ibu" yang dialirkan oleh ibu yang sarat kasih sayang telah membawa kesan yang besar kepada anak perempuannya yang mewarisi ilmu masakan ibunya, yang seterusnya memahami selok belok kehidupan sebagai seorang wanita. Hal ini telah diungkapkan pengarang sebagaimana contoh petikan berikut:

... Matanya merenung sayu ke muka Razali yang berusia awal 50-an itu. Sekali sekala matanya menjeling ke arah pinggan kaca putih jernih yang berisi bihun goreng berkuah laksa itu. ... Seleranya pada makanan itu tidak pernah pudar. Itulah makanan kegemarannya sejak zaman kanak-kanak lagi. Dia sendiri tidak menyangka betapa bihun goreng 
berkuah laksa yang menjadi kegemaran arwah mamanya, kini dia pula yang mewarisinya. (Nordin Saad, 2015: 3)

Seterusnya, cerpen "Kerana Kuih Koci” juga turut memperlihatkan "air tangan ibu" sebagai tunjang pendidikan untuk sebuah keluarga. Pengarang menyuguhkan peranan ibu sebagai seorang yang sangat prihatin terhadap keluarga dalam urusan mendidik anak-anak. Menerusi "air tangan" ibu yang menyediakan kuih koci telah juga mengasuh anak-anaknya agar mencintai ahli keluarga. Hidangan kuih koci dijadikan sebagai suatu lambang persaudaraan antara ahli keluarga untuk berkumpul menikmati hidangan minum petang. Kebersamaan ahli keluarga ketika menikmati "air tangan ibu" merupakan proses asuhan yang terbaik daripada seorang ibu untuk tumbesaran anak-anak. Cerpen ini membawa perutusan kepada pembaca bahawa keperibadian ibu yang mulia hasil daripada keprihatinannya dalam penyediaan juadah untuk anak-anak menjadikannya sebagai suatu pendidikan yang berguna, yang akhirnya memberikan kesan yang sangat besar dan bermakna kepada anakanaknya. Anak-anak didedahkan dengan ilmu masakan dan dapat mengenali warisan makanan Melayu. Penyediaan kuih koci labu dapat diketahui kaedah penyediannya, iaitu dengan senarai bahan-bahan seperti daun pisang, inti kelapa, dan kelapa parut. Pendidikan ilmu masakan ini secara langsung dapat membugarkan semangat anak-anak untuk memahami selok-belok kehidupan dalam sebuah keluarga seterusnya dalam hal ehwal rumah tangga apabila mereka dewasa kelak. Malahan, peranan ibu juga memberikan didikan dan menjelaskan tanggapan anak-anak terhadap sesuatu perkara. Watak utama dalam cerpen ini sebenarnya tidak menyenangi kuih-muih yang mengandungi inti kelapa dan kelapa parut, namun berkat kesabaran ibu mendidik anaknya dan berusaha memasak hidangan tersebut dengan "air tangan ibu", maka konflik ini dapat dileraikan. Ketidaksenangan anak terhadap inti kelapa dan kelapa parut dapat diatasi dengan belaian kasih sayang seorang ibu yang memiliki kesabaran yang tinggi dalam proses mendidik anak-anak. Hal ini diungkapkan pengarang seperti contoh petikan berikut:

Haruman kuih koci yang dikukus bersama daun pisang membangkitkan seleraku untuk menjamahnya. Selesai segala urusan, kami sekeluarga berkumpul di dapur. Menikmati hidangan minum petang. Air teh-O panas, kuih koci labu dan pisang goreng. Banyak kuih koci yang aku makan.Tiada lagi bayangan ulat-ulat kecil. Bukan kuih koci sahaja, sekarang semua jenis kuih yang ada inti kelapa dan kelapa parut aku boleh makan. (Fathul Khair, 2016: 8) 
Seterusnya cerpen "Serondeng Nasi Pulut" karya Jamilah Epin pula mengutarakan "air tangan ibu" sebagai tunjang pendidikan hasil daripada kesanggupan ibu menyediakan hidangan warisan tradisi kepada keluarga walaupun penyediaannya mengambil masa yang agak lama. Cerpen ini menampilkan keperibadian seorang ibu yang gigih memasak menu kelupis, salah satu hidangan tradisi masyarakat di bumi Kenyalang untuk mendidik anak-anak agar mencintai makanan warisan tersebut. Menerusi "air tangan ibu" yang cekal mengusahakan menu kelupis yang mengambil masa yang panjang, dan penyediaannya yang renyah, cerpen ini menawarkan proses asuhan yang terbaik kepada anak-anak untuk memahami makanan tradisi yang kian terpinggir kini. Anak-anak didedahkan dengan ilmu masakan menerusi cara memasak kelupis membawa kepada kecintaan terhadap warisan leluhur. Cara penyediaan masakan kelupis telah membawa anak-anak untuk mengenali bahan-bahannya seperti pulut, santan kelapa, dan daun palas. Malahan cara mengukus kelupis yang mengambil masa yang agak lama dapat mendidik anak-anak dengan sifat sabar dan tidak berputus asa untuk melakukan sesuatu perkara. Cara ini merupakan asuhan yang sangat bermakna hasil daripada "air tangan ibu". Kaedah penyediaan masakan kelupis ini sesungguhnya telah menampilkan keupayaan ibu meneruskan kelangsungan warisan tradisi keluarga. Hal ini sewajarnya menjadi contoh teladan kepada anak-anak agar mencintai warisan tradisi leluhur seterusnya mengekalkan jati diri dalam kehidupan. Hal ini dapat diperhatikan sebagaimana contoh petikan yang dinukilkan pengarang di bawah:

Mak sedang sibuk ulang-alik dengan kelupisnya. Istilah kelupis dalam loghat Sarawak ialah nasi pulut yang dimasak dengan air santan kelapa. Separuh masak, kemudian dibalut dengan daun palas. Kemudian, dikukus di dalam pengukus untuk memastikan ia betul-betul masak dan tahan lama. Paling lama pun bertahan sampai seminggu. Tidak basi terlalu cepat. (Jamilah, 2016: 42)

\section{(2) “Air tangan ibu” sebagai peringatan kebaikan}

Berdasarkan cerpen "Bihun Goreng Berkuah Laksa" menyerlahkan "air tangan ibu" sebagai inspirasi kepada anak-anak untuk mengharungi cabaran kehidupan. Cerpen ini memperlihatkan peranan ibu sebagai seorang yang gigih mendidik anak perempuannya menjadi remaja yang boleh menguruskan rumah tangga, malahan sangat menghormati kedua-dua orang tuanya. Hidangan bihun goreng berkuah laksa dijadikan pengikat kasih sayang 
antara ibu dengan anaknya, Nordiana Humairah untuk meladeni urusan keluarga. Cerpen ini mengungkapkan nilai kasih sayang yang ampuh antara ibu dengan anaknya, walaupun ibunya kini telah meninggal dunia. Pengarang mengutarakan keberkatan "air tangan ibu" dalam penyediaan juadah untuk anak perempuannya, iaitu menu bihun goreng berkuah laksa yang menjadi lambang kasih sayang yang berpanjangan. Hal ini demikian kerana Nordiana Humairah tetap mengingati setiap butir bicara dan nasihat allahyarhamah ibunya. hasil daripada hubungan antara kedua-duanya, khususnya hasil "air tangan" ibunya itu. Juadah bihun goreng berkuah laksa dijadikan sebagai pengikat kasih sayang seorang ibu ketika mendidik dan memberi pesan kepada anaknya agar menghormati bapanya dalam apa-apa sahaja situasi. Hal ini terungkap dalam contoh petikan di bawah:

Nordiana Humairah memerhati papanya dengan penuh kasih-sayang. Bihun goreng berkuah laksa yang sedang dinikmatinya itu ditolak ke tepi dengan cermat. Matanya tetap dihalakan ke wajah Razali yang duduk di hadapannya itu.Sememangnya begitu sikapnya.Nordiana Humairah amat menghormati papanya. Setiap tutur kata papanya akan didengari penuh teliti. Tidak pernah sama sekali dia membelakangi papanya atau menoleh ke arah lain tatkala bercakap dengan papanya. Itulah pesanan mamanya yang tidak mungkin dilupai. Dia masih ingat sangat pesanan itu, walaupun mamanya sudah hampir tiga tahun pulang ke rahmatullah. Dan pesanan arwah mamanya masih terus utuh dalam fikirannya seperti teguhnya ingatan Nordiana Humairah kepada mamanya itu. (Nordin, 2015: 2)

Seterusnya, cerpen "Kerana Kuih Koci”, juga turut menyerlahkan "air tangan ibu" sebagai peringatan kebaikan kepada anak-anak dalam sebuah kekeluargaan. Cerpen ini menampilkan sosok keperibadian seorang ibu yang menjadi sanjungan dan ingatan anak lantaran hasil daripada "air tangan ibu" yang menyediakan juadah untuk anak-anak. Hasil daripada keikhlasan ibu memasak dengan elemen keagamaan dan sentuhan kasih-sayang, maka telah melahirkan anak-anak yang bukan sahaja cemerlang dalam pendidikan bahkan paling utama berperibadi mulia. Pengarang menyuguhkan sahsiah ibu yang bersiap siaga menguruskan hal ehwal rumah tangga khususnya menyediakan hidangan masakan kuih koci untuk keluarga, dan ini telah menebarkan inspirasi untuk anak menyayangi ibunya dengan sarat kecintaan. Malahan cerpen ini menghantar perutusan bahawa "air tangan ibu" juga sebagai perutusan kebaikan untuk anak-anak menjadi soleh dan solehah. Kesedaran anak-anak terhadap pengorbanan ibu dalam mengasuh mereka 
bukan sekadar bersifat lahiriah bahkan membawa pengertian maknawi. Hasil daripada keperibadian ibunya yang menjadikan dapur sebagi medan untuk usaha mengasuh anak-anak menyerlahkan "air tangan ibu" sebagai peringatan kebaikan dalam beragama. Hal ini diungkapkan pengarang seperti contoh petikan berikut:

Sesungguhnya, air tangan daripada ibu mempunyai seribu satu hikmah. Setiap gaulan, dan sentuhan, disusuli selawat dan doa yang terbaik untuk anak-anaknya, agar menjadi insan yang soleh dan solehah serta berguna kepada sekalian marga masyarakat. Selama makanan itu terhadam di dalam jasad, selama itulah iringan doa ibu itu mengalir ke dalam pembuluh darah yang berselirat. (Fathul Khair, 2016: 9)

Seterusnya cerpen "Serondeng Nasi Pulut" turut menyerlahkan ibu sebagai peringatan kebaikan kepada anak-anak menerusi pendidikan. Walaupun ibu digambarkan hanya sebagai seorang suri rumah tangga, namun tetap berperanan membakar semangat anak-anaknya untuk mendalami ilmu agama. Cerpen ini menampilkan perihal ibu yang kurang memahami tentang hukumhakam dalam agama, namun tetap berusaha untuk memberikan pendedahan tersebut kepada anak-anaknya. Dalam konteks ini, ibu diperlihatkan sebagai seorang yang masih mempraktikkan adat dan budaya kuno. Kepercayaan ibu bahawa roh orang yang meninggal dunia akan pulang ke rumah pada hari raya dengan menyediakan hidangan makanan, namun telah dinasihati anak perempuannya agar tidak berbuat demikian kerana menyalahi agama Islam telah diterima dengan fikiran terbuka. Berkat "air tangan ibu" yang sentiasa menyediakan makanan untuk anak-anak membolehkan zuriatnya memahami agama Islam dengan lebih terperinci, dan akhirnya menangkis ibunya daripada kejahilan. Hubungan ibu dan anak menerusi masakan serondeng nasi pulut ternyata dapat membentuk akhlak anak-anak menjadi Muslim yang sempurna. Walaupun anak tersebut juga telah meninggal dunia, namun ilmu yang pernah dipelajari dan dikongsi dengan ibunya dapat memberikan pencerahan tentang agama kepada seluruh ahli keluarga yang lain. Hal ini dapat diperhatikan menerusi contoh petikan ini:

"Ya, mak faham. Syukurlah kakak kamu itulah yang banyak membimbing mak dan kita sekeluarga beriman kepada Allah Yang Esa dan banyak menerangkan ilmu agama kepada kita. Namun, Allah lebih sayangkan kakak kamu yang seorang itu ..." (Jamilah, 2016: 45) 
Berdasarkan cerpen "Bihun Goreng Berkuah Laksa", "air tangan ibu" sebagai pembentuk akhlak, anak terserlah menerusi watak Nordiana Humairah yang sangat menghormati papanya. Peranan sebagai seorang ibu yang membentuk akhlak anak disuguhkan pengarang menerusi perilaku Nordiana Hamzah yang sanggup menyediakan juadah bihun goreng laksa untuk papanya. Ikatan hubungan kasih sayang antara anak perempuan dengan ayah digembleng dalam cerpen ini menerusi "air tangan ibu" sebagai pembentuk akhlak terpuji. Hasil daripada masakan bihun goreng berkuah laksa yang pernah diajar allahyarhamah ibu Nordiana kepadanya menyebabkan anak gadis ini sangat menyayangi ahli keluarganya. Walaupun ibunya telah meninggal dunia, namun rasa kecintaannya terhadap ibunya tetap utuh dan ini dimanifestasikan kepada ayahnya pula menerusi menu bihun goreng berkuah laksa tersebut. Hal ini menunjukkan sahsiah diri seorang anak yang solehah yang bertanggungjawab memasak untuk ayahnya selepas kematian ibunya. Cerpen ini menyerlahkan bahawa "air tangan ibu" sebagai pembentuk akhlak anak-anak dan menerbitkan keceriaan dalam keluarga seperti contoh petikan berikut:

"Hah, ini bihun goreng dengan kuah laksanya, papa!" Suara Nordiana Humairah mengejutkan Razali. Dia meletakkan sepinggan bihun goreng yang sudah tersedia dengan kuah laksa yang masih berasap.

"Sedap betul baunya. Pandai anak papa masak,"puji Razali.

"Makan dulu pa, baru puji. Jangan-jangan baunya saja yang sedap," sahut Nordiana Humairah sambal tersenyum. Dia duduk di hadapan papanya. (Nordin, 2015: 7)

Seterusnya berdasarkan cerpen "Kerana Kuih Koci", "air tangan ibu" turut dikemukakan pengarang sebagai pembentuk akhlak anak-anak. Hasil daripada keikhlasan ibu memasak dengan elemen keagamaan dan sentuhan kasih sayang, maka telah melahirkan anak-anak yang bukan sahaja berperibadi mulia, malah bekerjasama dalam ikatan kekeluargaan. Peranan seorang ibu yang membentuk akhlak anak-anak menerusi "air tangan ibu" terserlah ketika menyediakan hidangan kuih koci. Ibu membentuk akhlak anak-anaknya agar prihatin dan berkorban masa demi menyediakan masakan untuk keluarga. Walaupun terpaksa berjaga malam untuk menyiapkan hidangan kuih koci, namun hasilnya amat bermakna untuk penyatuan kasih sayang dalam kekeluargaan. Cerpen ini menampilkan sosok peribadi wanita yang sanggup berkorban masa dan tenaga demi menyempurnakan tuntutannya sebagai 
seorang ibu dalam sebuah keluarga. Watak ibu ini dikemukakan sebagai seorang wanita mulia yang dapat dijadikan contoh teladan oleh anak-anak perempuannya dalam menguruskan hal ehwal rumah tangga khususnya dalam penyediaan hidangan sarapan untuk seisi keluarga. "Air tangan ibu" dalam cerpen ini berupaya menawarkan pembentukan akhlak kepada dua anak perempuannya, iaitu Kak Ipah dan Kak Ana agar turut menjadi wanita sebaik-baiknya apabila berkeluarga kelak. Hal ini terungkap dalam cerpen "Kerana Kuih Koci" seperti yang berikut:

Kami bersarapan bersama. Menjadi tradisi keluarga. Sarapan pagi hari Sabtu itu terdiri daripada kuih koci yang dibungkus emak malam tadi dengan Kak Ipah dan Kak Ana. Mereka sanggup berjaga malam untuk menyediakan sarapan pagi kami sekeluarga. (Fathul Khair, 2016: 5)

Cerpen "Serondeng Nasi Pulut" juga turut mengemukakan ibu sebagai pembentuk akhlak menerusi masakan khususnya dalam proses "air tangan ibu". Pengarang menampilkan sifat sabar seorang ibu yang sanggup menyediakan juadah kelupis untuk ahli keluarga walaupun penyediaannya memakan masa yang lama. Didapati cara menyediakan juadah kelupis yang menjadi tradisi nenek moyang orang Sarawak ini dipertahankan ibu untuk ahli keluarganya. Ibu mendidik anak-anak agar bersatu hati dan saling bantu-membantu di dapur supaya urusan penyediaan kelupis berjalan dengan lancar. Cerpen ini memperlihatkan sifat kesabaran ibu dan usahanya menyemai sikap saling bantu-membantu dalam kalangan anak-anak seperti contoh berikut:

"Hampir 50 gulung mak buat. Sekali rebus lagi, masak benarlah tu....", ujar mak kepadaku. Aku menyeringaikan wajah comelku di hadapan mak. Kemudian lalu menyempit di sebelah kak ambi, yang sedang memasukkan kuih sepit di dalam tin. Kak ambi minta aku ambilkan air untuk dia. Aku mencedok air di dalam udat, sejenis tembikar yang sebesar pemeluk orang dewasa dan setinggi meja makan. Udat digunakan untuk menyimpan air tadahan hujan. (Jamilah, 2016: 42)

\section{KESIMPULAN}

Berdasarkan penelitian, jelas memperlihatkan bahawa budaya makanan Melayu yang diketengahkan pengarang dalam cerpen "Kerana Kuih Koci", "Bihun Goreng Berkuah Laksa" dan "Serondeng Nasi Pulut" membawa kepada konsep "air tangan ibu". Hal ini demikian kerana pengarang telah mengemukakan watak ibu yang menjadi peneraju utama dalam cerpen 
masing-masing sebagai fokus utama dalam penyediaan hidangan untuk keluarga. Peranan ibu dengan perwatakan yang sabar dan gigih dalam hal menyediakan sajian untuk anak-anak sejajar dengan pandangan dalam Islam yang telah meletakkan martabatnya di tempat yang tinggi. Menerusi peranan ibu sebagai tunjang pendidikan, peringatan kebaikan, dan pembentuk akhlak telah menunjukkan "air tangan" amat penting dalam sesebuah institusi kekeluargaan.

Cerpen "Kerana Kuih Koci", "Bihun Goreng Berkuah Laksa" dan "Serondeng Nasi Pulut" berupaya menyerlahkan konsep "air tangan ibu" dalam budaya makanan Melayu dalam usaha melunasi tanggungjawab sebagai seorang wanita yang diamanahkan kepadanya mengikut tuntutan agama Islam.

\section{NOTA}

1. Bacaan lanjut, sila rujuk kajian Fithriani Gade, 2012. "Ibu Sebagai Madrasah Dalam Pendidikan Anak", Jurnal Ilmiah DIDAKTIKA, Agustus, hlm. 33 dan kajian Zulhamdani dan Mahfudz Masduki, 2015. "Ibu Dalam Al-Qur'an: Sebuah Kajian Tematik”, Jurnal ESENSIA, Vol. 16, No. 1, April 2015

\section{RUJUKAN}

Abdul Rashid Ngah. (2014). Ibu. Institut Terjemahan dan Buku Malaysia. Al-Quran dan terjemahan, 2010. Yayasan Restu Malaysia.

Abdullah, N. E. A., \& Abdullah, B., 2019. Peranan Wanita Muslimah dalam Dakwah kepada Keluarga dan Masyarakat [The Role of Women's Muslim in Da'wah to Family and Community]. Jurnal Islam Dan Masyarakat Kontemporari, 20(2), 16-27.

Asyraf Hj Ab Rahman, Wan Ibrahim Wan Ahmad \& Zainab Ismail, 2010. Peranan

Wanita dalam Pembangunan Keluarga dari Perspektif Fi Zilal Al-Quran, JGD

- Journal of Governance and Development, 14 Vol. 6, 2010 (14 - 21).

Che Wan Jasimah Bt. Wan Mohamed Radzi, 2009. Budaya Pemakanan Masyarakat

Malaysia Dari Perspektif Agama, Polisi, Sains Dan Teknologi Dengan Rujukan

Khusus Kepada Pengaruh Islam Dalam Penghasilan Makanan, Ijazah Doktor Falsafah. Universiti Malaya.

Fathul Khair Mohd Dahlan. (2016). Sfera Bersegi 5. Institut Terjemahan \& Buku Malaysia.

Fithriani Gade. (2012). Ibu sebagai madrasah dalam pendidikan anak. Jurnal Ilmiah DIDAKTIKA, XIII (1), 31-40 Agustus.

Ilani Mysara. (2010). Sesuci kasih bonda. Alaf 21 Sdn. Bhd.

Iwan Ghazali. (2013). Diari untuk ibu. Karangkraf. 
Jamilah Epin. (2016). Serondeng nasi pulut. Institut Terjemahan \& Buku Malaysia. Nordin Saad. (2015). Bihun goreng berkuah laksa. Institut Terjemahan \& Buku Malaysia.

Rohani Din. (2005). Diari bonda. Creative Enterprise Sdn. Bhd, 2005

Siti Nur Husna Abd Rahman, Mohd Izhar Ariff Mohd Kashim, \& Muhammad Adnan Pitchan. (2017). Peranan wanita dalam institusi kekeluargaan: perbincangan dari perspektif Islam. e-Bangi, Journal of Social Scieneces and Humanities, 12(3), 019 ISSN: 1823-884x.

Soo Cham. (2007). Airmata ibu. Dewan Bahasa dan Pustaka

Suhaila Mohamed \& Shaiful Bahri Md Radzi. (2015). Makan dan makanan dalam kesusasteraan Melayu, Jurnal Melayu, 14(2).

Zulhamdani dan Mahfudz Masduki. (2015). Ibu Ddalam al-Qur'an: Sebuah kajian tematik. Jurnal Esensia, 16(1), April. 